\title{
Anti-HIV, antitumor and immunomodulatory activities of paclitaxel from fermentation broth using molecular imprinting technique
}

\author{
Junhyok Ryang ${ }^{1 \dagger}$, Yan Yan ${ }^{1 \dagger}$, Yangyang Song ${ }^{1}$, Fang Liu ${ }^{1 *}$ and Tzi Bun $\mathrm{Ng}^{2^{*}}$
}

\begin{abstract}
In this study, a single component paclitaxel was obtained from fermentation broth by molecular imprinting technique, and its antiviral, antitumor and immunomodulatory activities were studied. The results showed that paclitaxel had a good inhibitory activity on human breast cancer MCF-7 cells and showed a concentration- dependent relationship with an IC50 of about $15 \mu \mathrm{g} / \mathrm{mL}$ in the sulforhodamine B assay. At the same time, paclitaxel exerted a weak inhibitory activity on cervical cancer Hela cells. In addition, paclitaxel not only inhibited the invasion of HIV-1 pseudovirus into cells, but also exhibited inhibitory activity to a certain extent after viral invasion of the cells. At a paclitaxel concentration of $20 \mu \mathrm{g} / \mathrm{mL}$, the inhibition of HIV-1 pseudovirus reached about $66 \%$. The inhibition of HIV-1 protease activity was concentration-dependent. At a concentration of $20 \mu \mathrm{g} / \mathrm{mL}$, the inhibitory effect of paclitaxel on HIV-1 protease was similar to that of the positive control pepstatin A, being 15.8\%. The HIV-1 integrase inhibiting activity of paclitaxel was relatively weak. Paclitaxel significantly up-regulated the expression of interleukin-6.
\end{abstract}

Keywords: Paclitaxel, Taxol, Antitumor activity, Anti-HIV activity, Molecularly imprinted polymer, Immunomodulatory activity

\section{Introduction}

Among plant-derived natural products, paclitaxel $\left(\mathrm{C}_{47} \mathrm{H}_{51} \mathrm{NO}_{14}\right)$, which was first isolated from the bark of the Pacific yew Taxus brevifolia, also known commercially as taxol, is a chemotherapeutic diterpenoid drug that exhibits potent anticancer activity (Kasaei et al. 2017; Zhou et al. 2010).

Due to its complex structure, unique medicinal mechanism and good anti-tumor activity, paclitaxel has been the subject of research of many scholars (Lasala et al. 2006; Oberlies and Kroll 2004). Moreover, paclitaxel has been studied for its potential for treating other diseases including neurodegenerative diseases and polycystic

\footnotetext{
*Correspondence: liufang312@nankai.edu.cn;

b021770@mailserv.cuhk.edu.hk

†Junhyok Ryang and Yan Yan contributed equally to this work

1 Department of Microbiology, The Key Laboratory of Molecular

Microbiology and Technology, Ministry of Education, College of Life Science, Nankai University, Tianjin 300071, China

${ }^{2}$ School of Biomedical Sciences, Faculty of Medicine, The Chinese

University of Hong Kong, Shatin, New Territories, Hong Kong, China
}

kidney disease (Zhang et al. 2005) and for the prevention of restenosis (Herdeg et al. 2000). Thus, paclitaxel is in high demand, and research interest in paclitaxel will continue to escalate (Li et al. 2017).

At present, the main source of paclitaxel is still dependent on the yew tree. Due to the increasing demand for paclitaxel, yew tree is on the verge of extinction, hence it is urgent to find a new way to produce paclitaxel (Ismaiel et al. 2017). Thus researchers aim at taxol production by means of several modern techniques including chemical synthesis, semi-synthesis method and plant tissue culture method. Nevertheless, these methods have both advantages and disadvantages (Ismaiel et al. 2017; Shankar Naik 2019). Kusari et al. (2012) reported that there has been tremendous interest in locating alternative sources of paclitaxel, including fungal endophytes (Kusari et al. 2012). In general, microbial fermentation has demonstrated that isolation and identification of taxol-producing fungi is a good strategy in the production of taxol (Ismaiel et al. 2017). Thus, developing a cost-effective paclitaxel fermentation process by microorganisms has 
become a sustainable solution (Shankar Naik 2019; Somjaipeng et al. 2015).

Molecular imprinting technology is a technique for preparing a polymeric material with the ability for recognizing a specific target molecule (template molecule). With the advancement of science and technology, molecular imprinting is now a mature technology, and numerous researchers deploy this technology to separate and obtain the target product (Li et al. 2017).

Therefore, MIP is widely employed for the separation and enrichment of active ingredients of natural products (Ishkuh et al. 2014). In recent years, the application of MIP technology in the separation of active ingredients of natural medicinal resources has received more and more attention.

For instance, some researchers have extensively investigated the interactions between paclitaxel and some common functional monomers, such as methacrylic acid (MAA), acrylamide (AM), 2-vinylpyridine (2-VP), and 4-vinylpyridine, in different solvents by ultraviolet spectrophotometry and found that the strongest interaction between paclitaxel and 2-VP in chloroform was observed at a ratio of 1:6 (Li et al. 2013, 2015). Ishkuh et al. (2014) have employed MSP using ethylene glycol dimethacrylate for preparing MIPs for paclitaxel with a high degree of crosslinking and found that the highest binding capacity for paclitaxel was $48.4 \%$. However, the particle sizes of the MIPs were mainly distributed around $100 \mathrm{~nm}$. Hence, despite its excellent imprinting effect, the MIPs could not be used further for separation and analysis (Ishkuh et al. 2014).

Compared with conventional separation techniques such as liquid-liquid extraction and column chromatography, molecular imprinting technology has the advantages of economy, speed and simplicity (Li et al. 2017).

At present, a large number of studies have established that paclitaxel exhibits high anticancer activity. Its antitumor mechanism involves binding to tubulin, formation of a stable tube bundle, leading to the loss of balance between dimers, and promotion of microtubule assembly polymerization (Li et al. 2017). Consequently, the cancer cells are arrested in the late $\mathrm{G}$ or M phase, mitosis of the cancer cells is inhibited, proliferation of the cancer cells is impeded, and the cells gradually shrink and eventually die. However, there are very few reports on other biological activities of paclitaxel such as inhibition of HIV-1 viral replication activity and regulation of immunity (Shankar Naik 2019; Wang et al. 2015). Wang et al. (2015) compared activities of taxol produced by endophytic fungi Nodulisporium sylviforme HDFS4-26 with that of taxol extracted from yew bark in inhibiting growth and inducing apoptosis of cancer cells (Wang et al. 2015). Cellular morphology, cell counting kit (CCK-8) assay, staining
(HO33258/PI and Giemsa), DNA agarose gel electrophoresis, and flow cytometry (FCM) analyses were used to determine the apoptosis status of cancer cell lines such as MCF-7 cells, HeLa cells, and ovarian cancer HO8910 cells. The fungal taxol exhibited cytotoxic activity against HeLa cancer cell lines in vitro and displayed antifungal and antibacterial activities against different pathogenic strains (Das et al. 2017).

In this study, paclitaxel samples obtained from endophytic fungus fermentation broth by molecular imprinting and solid phase extraction were used to investigate the antiviral, antitumor and immunomodulatory activities of the paclitaxel, which enriched the application value of paclitaxel. It is speculated that the intrinsic relationship between malignant tumor and AIDS is pointed out. It supports a theoretical foundation for the future diagnosis of potential diseases.

\section{Materials and methods Materials}

Fermentation broth is commercial lyophilized powder (Professor Xudong Zhu Laboratory, State Key Program of Microbiology and Department of Microbiology, College of Life Sciences, Nankai University, Tianjin, China). 4-Vinylpyridine (4-vp) was purchased from Across Organics (USA). Methacrylic acid (MAA) and ethylene glycol dimethacrylate (EGDMA) were obtained from Aldrich (USA). Acrylamide (AA) was obtained from Union Star Biotechnology Co., Ltd, Tianjin, China. 2,2'-azobisisobutyronitrile (AIBN) (Kuwait Company, Tianjin, China) was recrystallized in ethanol before use. Dimethyl sulfoxide (DMSO) was purchased from Sigma (USA). Paclitaxel (>98\%) was purchased from Shanghai Jinhe Biotechnology Co., Ltd. Methanol, acetone, tetrahydrofuran and isooctane were of HPLC grade. Other reagents were of analytical grade.

\section{Cell lines and cell culture}

All cell lines were kindly provided by Professor Wentao Qiao (Department of Microbiology, Nankai University) and maintained in DMEM supplemented with $10 \%$ fetal bovine serum (Gibco, Invitrogen), $100 \mathrm{IU} / \mathrm{mL}$ of penicillin and $100 \mu \mathrm{g} / \mathrm{mL}$ of streptomycin at $37{ }^{\circ} \mathrm{C}$ in a humidified atmosphere of $95 \%$ air $/ 5 \% \mathrm{CO}_{2}$.

\section{Preparation of molecularly imprinted polymers}

MAA was selected as the functional monomer. Acetone was the porogen, EGDMA was the crosslinking agent, AIBN was the thermal initiator, and the ratio of the template: functional monomer: crosslinking agent used was 1:6:30. The template was synthesized. Affinity and transfer selectivity of molecularly imprinted polymers. The template molecules were removed when preparing the 
non-imprinted polymer, and the remaining steps were performed in the same manner as described above for the imprinted polymer.

\section{MIP-SEP procedures}

Two hundred milligrams of the prepared polymer as a filler were accurately weighed, and added to an empty solid phase extraction column ( $3 \mathrm{~mL}, 8 \mathrm{~mm}$ in diameter). The solid phase extraction column was made of polypropylene. The commercial joints and interfaces have been standardized and can be directly connected to the vacuum device. The upper column sample was dissolved in methanol: water $(2: 8, \mathrm{v} / \mathrm{v})$, while the SPE cartridge was equilibrated with the same mixture of methanol and water. A mixed solution of methanol and water was used as a washing solution in the solid phase extraction process. Using methanol: glacial acetic acid $(9: 1, \mathrm{v} / \mathrm{v})$ as eluent, the collected eluent was rotary evaporated to remove all solvents, and then the enriched product was dissolved in $2 \mathrm{~mL}$ of methanol, and analyzed by HPLC.

\section{Preparation of samples}

Ten gram lyophilized fermentation broth was dissolved in $100 \mathrm{~mL}$ of distilled water and filtered. The filtered liquor was evaporated under reduced pressure and then dissolved in $100 \mathrm{~mL}$ of methanol.

The extract was partitioned in a mixture of dichloromethane: $n$-hexane: methanol $(5: 4: 1, \mathrm{v} / \mathrm{v} / \mathrm{v})$ and the fraction in the lower layer was evaporated under reduced pressure. The crude paclitaxel was dissolved in a mixture of methanol: water $(1: 9, \mathrm{v} / \mathrm{v})$ and processed as described in 2.3 .

\section{High-performance liquid chromatographic (HPLC) analysis}

The analysis was performed using a LabAlliance highperformance liquid chromatographic instrument equipped with an ultraviolet detector at $280 \mathrm{~nm}$. All separations were achieved on an analytical reversed-phase Kromasil 100-5 C18 column $(4.6 \mathrm{~mm} \times 250 \mathrm{~mm})$. The injection volume was $20 \mu \mathrm{L}$, and the flow rate was maintained at $1.0 \mathrm{~mL} / \mathrm{min} . \mathrm{H}_{2} \mathrm{O}$ 0.05\% $\mathrm{HAc} \mathrm{MeOH}$ (30:70) was used as a mobile phase.

\section{Assay of antitumor activity}

The inhibitory effects on tumor cell lines were determined using the protein-staining sulforhodamine $B$ (SRB) assay based on the ability of the SRB dye to bind basic amino acid residues on proteins (Skehan et al. 1990) which is similar in performance to the MTT (dimethylthiazol-diphenyltetrazolium bromide) assay as assays of cytotoxicity. Different human cell lines, including embryonic kidney 293T, cervical cancer HeLa and breast cancer MCF-7 cells were taken as targets for the paclitaxel sample. The various cell lines were maintained in DMEM medium supplemented with streptomycin, penicillin and FBS at $37{ }^{\circ} \mathrm{C}$ in a humidified atmosphere of $5 \%$ $\mathrm{CO}_{2} .100 \mu \mathrm{L}$, cell suspension $\left(1 \times 10^{5}\right.$ cells $\left./ \mathrm{mL}\right)$, with cells in the exponential growth phase, were seeded into each well of a 96-well culture microplate. After incubation for $24 \mathrm{~h}$, paclitaxel solution was added and incubation was continued for another $48 \mathrm{~h}$. The cells were fixed in cold trichloroacetic acid $(25 \mu \mathrm{L}, 50 \%)$ and stained with $0.4 \%$ SRB solution. The protein-bound SRB dye was solubilized with $100 \mu \mathrm{L}$ Tris- $\mathrm{HCl}$ buffer (10 mM, pH 7.4) for determination of the optical density (OD) at $490 \mathrm{~nm}$. The negative control was composed of cells treated with DMSO. The vehicle control was composed of cells without any treatment.

$$
\begin{aligned}
\text { Cell viability }(\%)= & (\text { mean OD of treated cells } / \\
& \text { mean OD of vehicle treated cells }) \\
& \times 100 \%
\end{aligned}
$$

Inhibition Rate $(\%)=(1-$ mean OD of treated cells/ mean $O D$ of vehicle treated cells) $\times 100 \%$.

\section{Assays of anti-HIV activity \\ Assay of inhibition of HIV-1 entry}

TZM-BL-croGFP cells were cultured at $37{ }^{\circ} \mathrm{C}$, in $5 \%$ $\mathrm{CO}_{2}$. When the cell density was $80-90 \%$, the cells were digested with trypsin, and the cells were collected at $1000 \mathrm{~g}$ for $3 \mathrm{~min}$. The PBS buffer was washed repeatedly 3 times. The cell density was adjusted to $10^{5} \mathrm{cell} / \mathrm{mL}$. The MIPs of different concentrations to be tested were added $2 \mathrm{~h}$ before the addition of HIV-1 pseudovirus and $2 \mathrm{~h}$ after the addition, and the culture was continued for $24 \mathrm{~h}$. The medium in the well was aspirated and $150 \mu \mathrm{L}$ of cell lysate was added. The cells were fully lysed by reaction at room temperature for $15 \mathrm{~min}$.

After the lysis was completed, the cell lysate was collected and the supernatant was collected by centrifugation at $5000 \mathrm{~g}$ for $1 \mathrm{~min}$. Then $200 \mu \mathrm{L}$ of the supernatant were removed and mixed evenly with $50 \mu \mathrm{L}$ of luciferase substrate solution in a 96-well plate. The mixture was placed in a luciferase luminescence detector for determination of the fluorescence intensity at $560 \mathrm{~nm}$ (Is). The blank control was free of pseudovirus $(I b)$. The negative control consisted of only the pseudovirus but without the sample (In). AZT was used as the positive control.

The inhibition of the entry of pseudovirus into the cell was calculated as follows:

$$
\text { Inhibition rate }(\%)=(I n-I s) /(I n-I b) \times 100 \% \text {. }
$$




\section{Assay of HIV-1 protease inhibitory activity}

The strain used was E. coli BL21-pPR (a plasmid containing the HIV-1 protease gene). The cells were cultured in $\mathrm{LB}$ medium for $12 \mathrm{~h}$. Then $50 \mu \mathrm{L}$ of the bacterial solution was transferred to $4 \mathrm{~mL}$ of fresh LB liquid medium containing $50 \mu \mathrm{g} / \mathrm{mL}$ kanamycin sulfate. The test sample and $40 \mu \mathrm{M}$ inducer IPTG were added before culture at $37^{\circ} \mathrm{C}$.

A $100 \mu \mathrm{L}$ aliquot was taken at hourly intervals into a 96-well plate. The growth of the cells was determined by measurement of absorbance at a wavelength of $490 \mathrm{~nm}$. The cell culture time was taken as the horizontal and vertical coordinates, and the absorbance was plotted on the ordinate. The growth curve of the cells was drawn, the slope $\mathrm{K}$ was calculated, and the inhibition rate of the HIV-1 protease expression was calculated according to the slope. The protease inhibitor Pepstatin A was used as a positive control; in the negative control, LB medium was used instead of the sample, and the absorbance was $\mathrm{K} 0$; in the blank control, the LB medium was used instead of the sample, and the absorbance was K1, but no IPTG was induced; the absorbance of each sample system was Ks.

The HIV-1 protease inhibitory activity was calculated as follows:

Inhibition rate $(\%)=(K s-K 0) /(K 1-K 0) \times 100 \%$.

\section{Assay of HIV-1 integrase inhibitory activity}

The plasmid pET28a-LTR cloned with HIV-1 LTR was transformed into E. coli DH5(R) strain, and the plasmid was extracted after expansion and culture. Then the following $10-\mu \mathrm{L}$ reaction system was constructed: $1 \mu \mathrm{L}$ Tris$\mathrm{HCl}(20 \mathrm{mM}, \mathrm{pH}$ 8.0) buffer, $1 \mu \mathrm{L} \beta$-mercaptoethanol $(2 \mathrm{mM}), 1 \mu \mathrm{L} \mathrm{MnCl} 2(2 \mathrm{mM}), 1 \mu \mathrm{L}$ sample at different concentrations, $3 \mu \mathrm{L}$ substrate plasmid and $3 \mu \mathrm{L}$ of HIV-1 integrase $(10 \mathrm{pmol})$ were incubated at $37^{\circ} \mathrm{C}$ for $30 \mathrm{~min}$ followed by agarose gel electrophoresis.

In this experiment, the control was DBZ, the negative control was Tris- $\mathrm{HCl}$ buffer (10 mM, pH 7.4) instead of the sample, and the blank control was Tris- $\mathrm{HCl}$ buffer instead of the sample and no HIV-1 integrase was added.

\section{Determination of cytokine gene expression levels}

Female BALB/c mice (7 weeks old, 20-25 g) were obtained from the Chinese Academy of Military Medical Sciences Laboratory Animal Center. The procedures of all animal experiments had been approved by the Chinese Academy of Military Medical Sciences Animal Research Ethics Committee. Ten BALB/c mice were randomly divided into 2 groups, a control group and a paclitaxel group, with 5 mice in each group. Normal saline was injected intraperitoneally into the control group. The MIPs group was injected intraperitoneally with a dose of
$50 \mathrm{mg} / \mathrm{kg}$ for 7 consecutive days and once daily. On the 8th day, both groups of mice were treated with lipopolysaccharide at a dose of $3 \mathrm{mg} / \mathrm{kg}$ and euthanized after $12 \mathrm{~h}$.

The total splenic RNA was isolated by using the Trizol kit. The reaction mixture was composed of $1-5 \mu \mathrm{g}$ total RNA, $0.5 \mathrm{mM}$ dNTPs, 50 ng oligo (dT) primer, reverse transcription buffer, and 3 units of reverse transcriptase. It was heated at $65^{\circ} \mathrm{C}$ for $5 \mathrm{~min}$, then conducted at $42{ }^{\circ} \mathrm{C}$ for $30 \mathrm{~min}$, and finally inactivated by heating to $95^{\circ} \mathrm{C}$ for $5 \mathrm{~min}$. The primers for real-time quantitative PCR were shown in Additional file 1: Table S1 and the system for real-time quantitative PCR was shown in Additional file 1: Table S2.

The following thermocycler program was used for realtime PCR: $1 \mathrm{~min}$ pre-incubation at $95{ }^{\circ} \mathrm{C}$, followed by 40 cycles of incubation at $94{ }^{\circ} \mathrm{C}$ for $15 \mathrm{~s}, 55^{\circ} \mathrm{C}$ for $30 \mathrm{~s}$, $72{ }^{\circ} \mathrm{C}$ for $45 \mathrm{~s}$. The $2^{-\Delta \Delta \mathrm{Ct}}$ method was used to analyze the results. GAPDH was the internal control.

Determination of cytokine gene expression levels was calculated as follows:

$$
\begin{aligned}
& \Delta \mathrm{Ct}=C t_{(\text {Target gene })} \\
& \quad-C t_{G A P D H}(\text { amplification from the same cDNA })
\end{aligned}
$$

$$
\Delta \Delta \mathrm{Ct}=\Delta C t_{(\text {Treated })}-\Delta C t_{(\text {Control })} .
$$

\section{Statistical analyses}

Results were expressed as mean \pm standard deviation (SD). Statistical significance was evaluated using analysis of variance (ANOVA, SPSS software version 22; IBM Corp., NY) test followed by the least significant difference (LSD) test at $p \leq 0.05$ level.

\section{Results \\ Preparation and HPLC analysis of paclitaxel by molecularly imprinted method}

The presence of paclitaxel in the crude extracts was confirmed by HPLC analysis. As shown in Fig. 1a, in the fermentation broth, compared with paclitaxel standard, starting peak appeared at the same retention time of about $13 \mathrm{~min}$, which proves that the crude extract from the fermentation broth contains paclitaxel, by the way, the composition of the product was complex as well as the content of paclitaxel was smaller than that of other ingredients.

Figure $1 \mathrm{~b}$ shows that, after crude extract was treated by the molecularly imprinted column, the impurities were almost completely separated, and paclitaxel in the sample was considerably enriched and the homogeneity was greatly enhanced.

Compared with the paclitaxel standard, the target material was seldom contained in the crude extract. The 


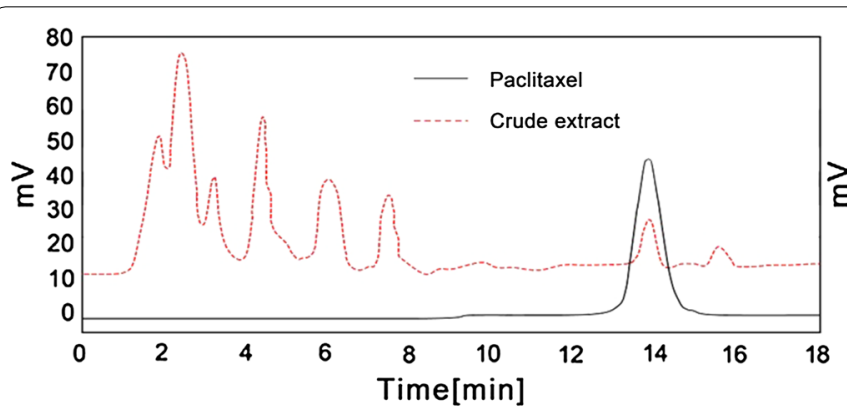

a

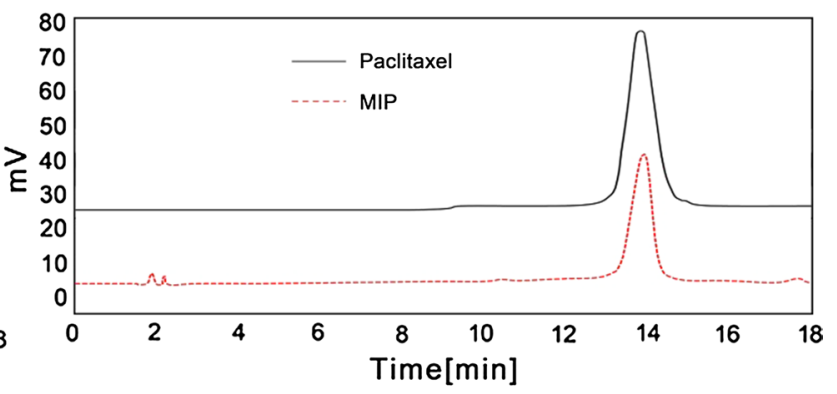

b

Fig. 1 HPLC diagram of paclitaxel from the fermentation broth (a paclitaxel standard and crude extract, $\mathbf{b}$ paclitaxel standard and MIPs)

solution of MIPs eluted was mostly paclitaxel with only a minute extraneous peak. It proved that the synthesized molecularly imprinted polymer had a substantial enriching effect on the extraction of paclitaxel from the fermentation broth.

\section{Morphological characterization of the MIPs}

The apparent morphology of the polymer surface was observed directly by SEM to gain an intuitive understanding of the polymer. In the MIPs, the roughness of the particle surface itself causes the increase in the surface area compared with the NIPs, which possessed a uniform, compact, and smooth shape. The nonporous structure in the NIPs particles was due to the lack of specific binding sites which were created for MIPs and suggested that the MIPs had great potential in application as sorbents (Fig. 2).

\section{Effect of paclitaxel on tumor cell proliferation}

As shown in Fig. 3a, when MIPs concentration was $20 \mu \mathrm{g} /$ $\mathrm{mL}$, there was no significant effect on embryonic kidney $293 \mathrm{~T}$ cells $(p>0.05)$. Moreover, the damage to the cells caused by the addition of DMSO was negligible.
As can be seen from Fig. 3b, the antitumor activity of the paclitaxel standard was slightly higher than that of MIPs at the same concentration. However, MIPs also exhibited good antitumor activity with an $\mathrm{IC}_{50}$ of $15 \mu \mathrm{g} /$ $\mathrm{mL}$ for human breast cancer MCF-7 cells in a concentration- dependent manner. In Fig. 3c, paclitaxel inhibited cervical cancer Hela cells by $40 \%$ at $20 \mu \mathrm{g} / \mathrm{mL}$, and the antitumor activity against Hela cells was significantly lower than that of MCF-7 cells, which might be related to the mechanism of action. However, concentration dependence was also observed.

\section{Inhibitory effect of paclitaxel on the entry of HIV-1 pseudovirus}

The life cycle of hiv shows HIV-1 enters host cells after $1-2 \mathrm{~h}$ of infection, adsorption inhibitors must be added before HIV-1 infects host cells to have a corresponding effect. In this study, samples were added before and $2 \mathrm{~h}$ after infection. AZT (zidovudine, a listed nucleoside reverse transcriptase inhibitor) was used as the control group to test the inhibitory effect of the paclitaxel of different concentrations on the entry of hiv- 1 pseudovirus into TZM-BL cells.

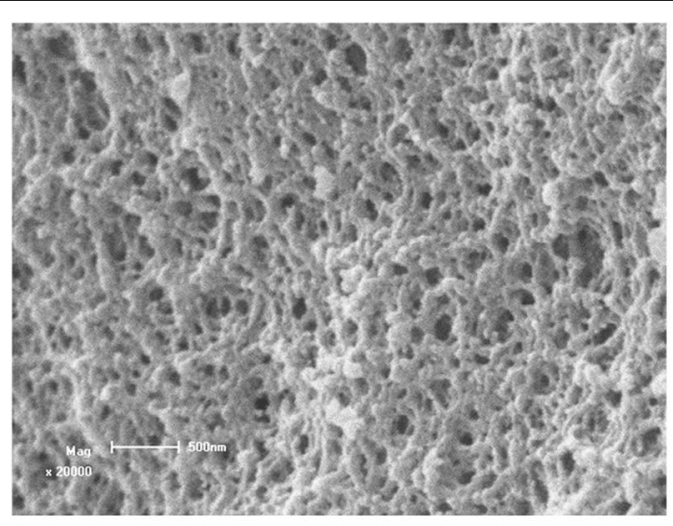

a

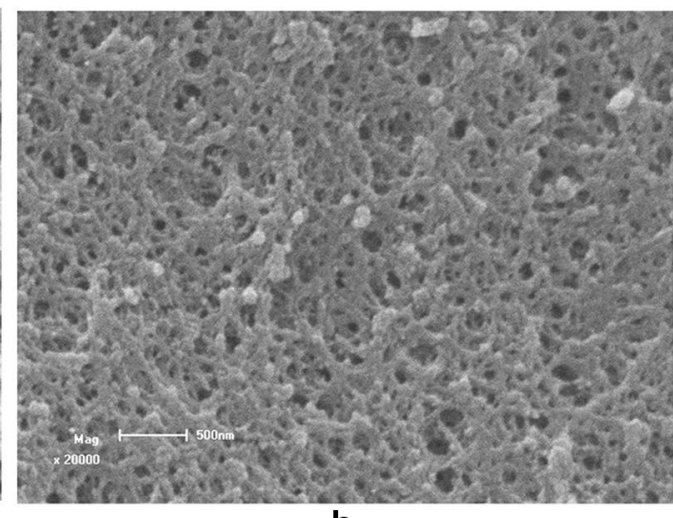

b

Fig. 2 Scanning electron micrographs of the MIPS (a) and NIPs (b) 

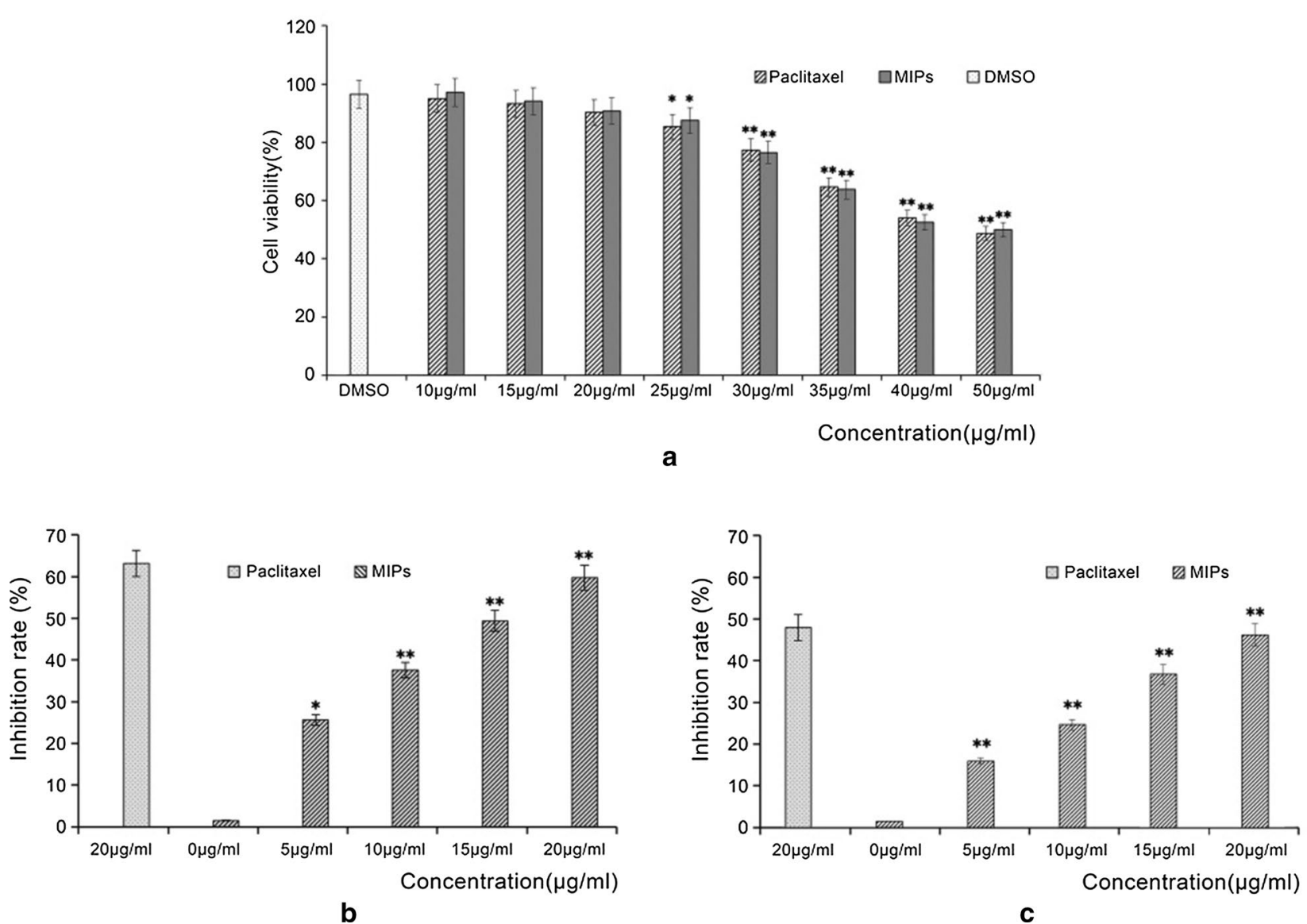

Fig. 3 Antitumor activity of paclitaxel. a Cytotoxicity of paclitaxel on 293T cells; $\mathbf{b}$ inhibitory activity of paclitaxel on MCF-7 cells; c inhibitory activity of paclitaxel on Hela cells. ${ }^{*} p<0.05,{ }^{* *} p<0.01$ versus non-treatment with MIPs

As shown in Fig. 4, the positive control azidothymidine (AZT) maintained potent inhibitory activity before and $15 \mathrm{~h}$ after infection. The inhibition rate was $90 \%$, and there was no significant difference before and after infection $(p>0.05)$. This indicates that AZT can inhibit the entry of HIV-1 pseudovirus to a certain extent, but it does not target the process of virus invasion.

In the pre-protected group, both the paclitaxel standard and MIPs manifested good inhibitory activity, although the paclitaxel sample displayed better and concentration-dependent inhibitory activity. Although the inhibition rate decreased after $2 \mathrm{~h}$ of infection, the difference was not significant $(p>0.05)$, indicating that the paclitaxel sample had similar inhibitory activity toward AZT in the process of HIV-1 pseudovirus entry. The target is not limited to viral entry.

\section{Inhibitory effect of paclitaxel on HIV-1 protease activity}

Pepstatin A (an HIV-1 protease inhibitor) served as a positive control. At $80 \mu \mathrm{g} / \mathrm{mL}$, pepstatin A brought about a certain degree of recovery of cell growth (Fig. 5). As shown in Fig. 5, the paclitaxel sample inhibited HIV-1 protease, but the naturally extracted paclitaxel sample inhibited protease activity to a less extent than the paclitaxel standard. This might be due to the damage of the biological activity of paclitaxel caused by the extraction process. However, at an effective concentration of $20 \mu \mathrm{g} /$ $\mathrm{mL}$, the inhibitory effect of paclitaxel on HIV-1 protease was approximately similar to that of the positive control pepstatin A $(80 \mu \mathrm{g} / \mathrm{mL})$. Thus paclitaxel demonstrated good HIV-1 protease inhibitory activity.

\section{Inhibitory effect of paclitaxel on HIV-1 integrase activity}

In the in vitro assay model, the purified His-tagged HIV-1 integrase was applied to the substrate plasmid pET28aLTR using HIV-1 integrase. The cleavage activity of the sample inhibiting HIV-1 integrase was characterized by detecting changes in plasmid linearity. The positive control used was raltegravir (the only commercially available HIV-1 integrase inhibitor). As shown in Fig. 7, raltegravir was able to significantly inhibit integrase cleavage activity, and the open-loop state of the plasmid under its 


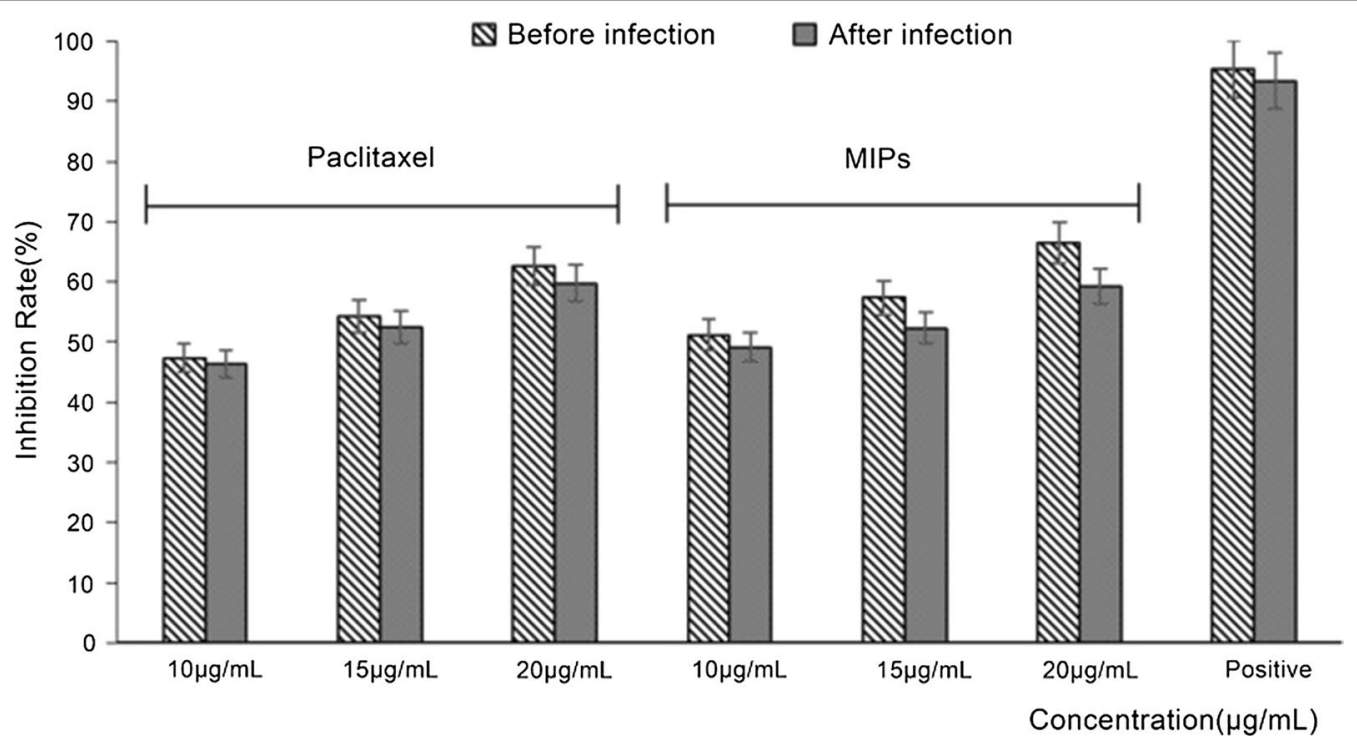

Fig. 4 Inhibitory effects of paclitaxel on HIV-1 entrance activation induced by pseudovirus. "Positive" refers to the positive control AZT

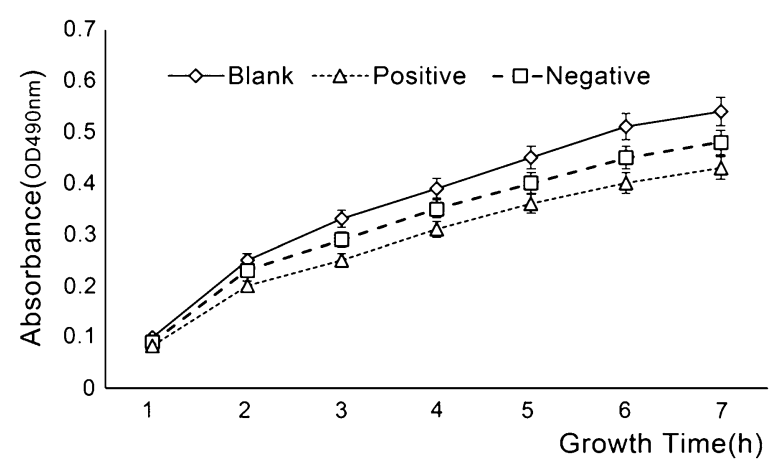

Fig. 5 Effect of HIV-1 protease on IPTG-induced E. coli growth. (Positive control: E. coli in the presence of IPTG and pepstatin A; negative control: E. coli in the presence of IPTG; blank control: E. coli only)

action was comparable to that of the blank control group. The inhibitory activity of MIPs was better than the negative control.

\section{Effect of MIPs on cytokine gene expression}

As shown in Fig. 8, the total RNA of mouse spleen lymphocytes was clearly separated into three bands. The upper two bands were 28s rRNA and 18s rRNA. The two bands were well separated and the integrity of the sample was good, and the next one was 5s rRNA. The A260/ A280 values were 2.05 and 2.05 respectively, indicating high RNA purity, and the samples could be reverse transcribed and further experiments could be conducted.

The increase of DNA products was monitored in real time by determining the change of fluorescence intensity.
As shown in Fig. 9, after the intraperitoneal injection of MIPs, there were some changes in the cytokines, especially the expression of IL-6 was significantly up-regulated. IL-6 responded to tissue damage and stimulated the production of other cytokines. As an anti-inflammatory factor, IL- 6 can inhibit TNF- $\alpha$, IL-1 and IL-10. It was found from the table that both TNF- $\alpha$ and IL-10 were down-regulated, while IFN- $\gamma$ and IL-4 remained almost unaltered.

\section{Discussion}

Paclitaxel (taxol) belonging to a class of complex diterpenoids, called taxanes is a effective anti-cancer drug against breast cancer, and it has received extensive attention due to its unique anticancer mechanism. Initially, paclitaxel was isolated from the bark of yew (Shankar Naik 2019). Since then, paclitaxel has been isolated from some plants belonging to genus Taxus (family Taxaceae, syn Coniferales) and other genera of the same family such as AmenoTaxus, Austro Taxus, PseudoTaxus (Flores-Bustamante et al. 2010; Hao et al. 2013). The traditional methods of extracting paclitaxel from the bark of Taxus species have the disadvantage of high cost and environmental damage. Unprecedented yew cutting, low amounts of paclitaxel production, laborious and slow process of paclitaxel extraction prompted the discovery of the alternative source of paclitaxel (Flores-Bustamante et al. 2010). Thus researchers focus on paclitaxel production by means of several modern techniques, for example chemical synthesis, and plant tissue culture (Jennewein and Croteau 2001) and microbial fermentation etc. (Frense 2007; Visalakchi and Muthumary 2010). 
Each method has its own pros and cons. However, by microbial fermentation method, it is easy to reduce costs of production and increase the yield of paclitaxel, which is very economic and practical. In general, microbial fermentation has demonstrated that isolation and identification of taxol-producing fungi is a good strategy in the production of paclitaxel.

Molecular imprinting technology is now mature, and many researchers use this technology to separate and obtain the desired product (Li et al. 2013, 2015). In the process of synthesizing molecularly imprinted polymers, the difficulty lies in the choice of functional monomers and porogens. Since the structure of paclitaxel has various functional groups such as a phenolic hydroxyl group, an ester group, an amino group, and a hydroxyl group, it has both an acidic as well as a basic functional monomer (Li et al. 2015).

Previously, we studied MAA (acidic), AM (neutral) and 4-vp (alkaline) as functional monomers. The results showed that when MAA was used as a functional monomer, it had good specificity for the enrichment of paclitaxel, and the recovery attained was $70 \%$. At the same time, acetone was found to have good specificity as a porogen, and the recovery was $83 \%$. In addition, when the ratio of the template: functional monomer: crosslinker was 1:6:30, the adsorption rate and recovery rate of the paclitaxel sample are the highest.

After the molecularly imprinted polymer was determined, the crude paclitaxel in the bark of the yew was first examined by HPLC to determine whether it had an enrichment effect (Li et al. 2017). Figure 1 shows that a single component consistent with the retention time of the paclitaxel standard was obtained, indicating that the synthesized molecularly imprinted polymer has a specific enrichment effect on the paclitaxel sample.

Paclitaxel has been reported to have good antitumor activity, especially against MCF-7 cells (Kasaei et al. 2017; Wang et al. 2015). In this study, we examined the antitumor activity of the enriched paclitaxel samples. The experimental results show that the paclitaxel sample enriched by the synthesized molecularly imprinted polymer exhibited a good anti-proliferative activity toward both MCF-7 and Hela cells (Figs. 3, 4). Moreover, the antitumor activity of the paclitaxel sample was higher than that of the paclitaxel standard. It is speculated that the activity of the natural product was retained, and the antitumor activity was displayed.

Up to now, there are few reports on the antiviral activity of paclitaxel (Krawczyk et al. 2005; Stebbing et al. 2003), in particular, there are very few reports on

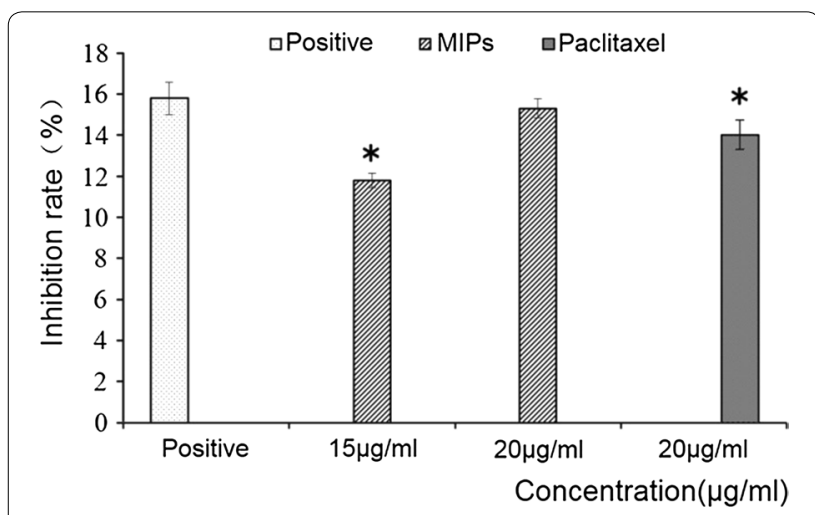

Fig. 6 Inhibitory effects of different concentrations of paclitaxel, MIPs and pepstatin $\mathrm{A}$ on $\mathrm{HIV}-1$ protease. ${ }^{*} \mathrm{p}<0.05,{ }^{* *} \mathrm{p}<0.01$ versus positive

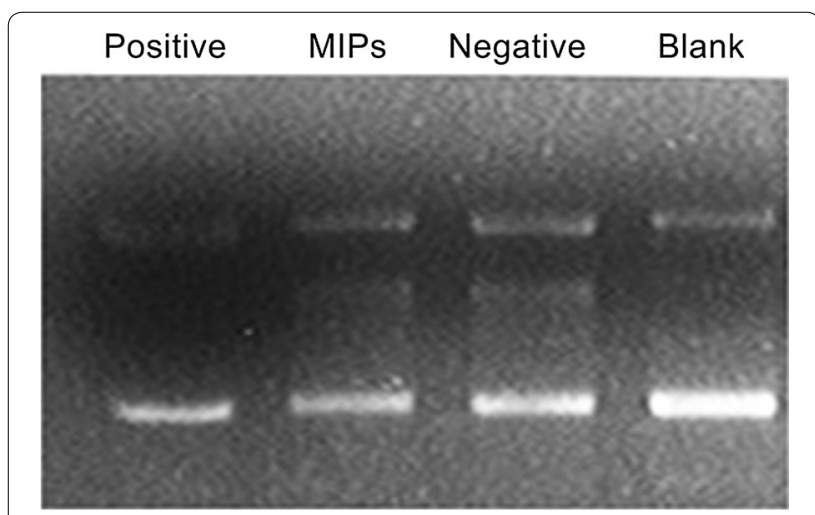

Fig. 7 Inhibitory effect of paclitaxel on HIV-1 integrase

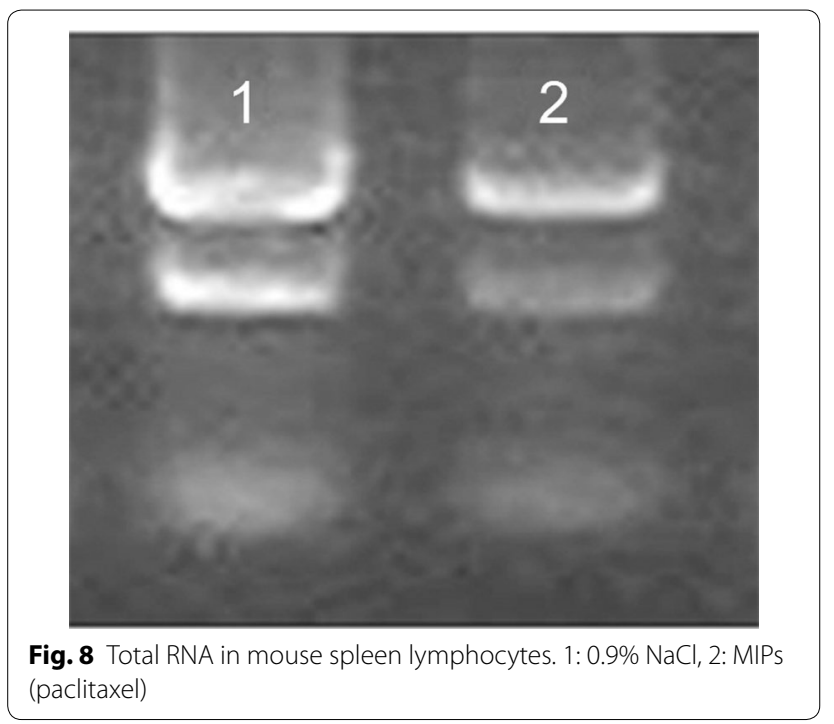




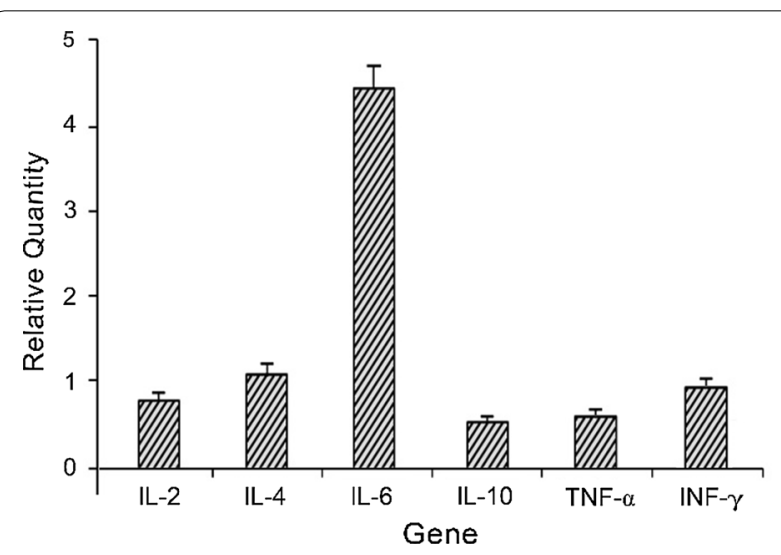

Fig. 9 Effects of MIPs on the expression of target genes $(n=5)$

anti-HIV activity of microbial paclitaxel by molecular imprinted polymer. In this paper, we explored the potential of paclitaxel in the prevention and treatment of AIDS and conducted research in three areas: HIV-1 viral invasion, HIV-1 protease activity, and HIV-1 integrase activity. Based on the life cycle of viral replication, we designed to add paclitaxel samples $2 \mathrm{~h}$ before virus invading cells and $2 \mathrm{~h}$ after invasion, and to determine whether paclitaxel samples inhibit HIV-1 virus invasion into host cells with a fluorescence microplate reader.

Paclitaxel sample inhibited the entry of HIV-1 virus into TZM-BL cells, and addition of the pre-invasive drug had a higher inhibition rate on the virus, indicating that in future practice, the method of preventive dosing can be employed to prevent and treat AIDS more effectively (Fig. 4).

Interestingly, the paclitaxel sample not only acts on the process before the virus invades, but also has an inhibitory effect upon viral invasion of the host cells. This result provides a theoretical basis for the subsequent inhibition of HIV-1 protease and integrase activity by paclitaxel samples (Figs. 5, 6, 7).

The results showed that the paclitaxel sample had different inhibitory activities against the two enzymes and had stronger HIV-1 protease inhibitory activity. We assumed that it may be related to the model of detection. The test of integrase inhibition is an in vivo detection model that can directly act on host cells; the assay of protease inhibition is an in vitro detection model, but only the degree of cleavage of the plasmid is detected.

The body is in an immune-regulated state under normal conditions, and once stimulated by the outside world, the immune system will be disordered (Yuan et al. 2010). Therefore, we can detect the effect of paclitaxel samples from the aspect of cytokine changes. Under normal conditions, the body's immune cells Th1/Th2 are in dynamic equilibrium (Yuan et al. 2010).
Many studies have disclosed that in the early stage of HIV-1 virus-infected host, the immune balance is disrupted, causing the immune cells Th1 to shift to Th2, and the immune-related cytokines are characterized by down-regulation of IL-2 and up-regulation of IL-4 and IL-10, and The pro-inflammatory factor TNF- $\alpha$, which is closely related to the virus, is activated, allowing NF-kB to bind to the LTR of HIV-1 virus, thereby activating viral replication, causing immune imbalance and disease progression (Coghill et al. 2017; Otiti-Sengeri et al. 2018). As shown in Fig. 9, MIPs can down-regulate the expression of IL-10 and up-regulate the up-regulation of IL-6, which has a certain positive effect on balancing the cytokines in immune imbalance.

In this study, we obtained paclitaxel from the fermentation broth of endophytic fungus by molecular imprinting technology and MIPs were used to investigate the antiviral activity, antitumor activity and immunomodulatory effects of the paclitaxel. The findings enriched the application value of paclitaxel, and provided theoretical support for the development of small molecule natural products.

\section{Supplementary information}

Supplementary information accompanies this paper at https://doi. org/10.1186/s13568-019-0915-1.

Additional file 1: Table S1. Primers for real-time quantitative PCR

Table S2. Systems for real-time quantitative PCR.

\section{Abbreviations}

MIPs: molecular imprinted polymers; NIP: non molecularly imprinted polymer; 4-vp: 4-vinylpyridine; MAA: methacrylic acid; AA: acrylamide; EGDMA: dimethacrylate; AIBN: 2,2'-azobisiso-butyronitrile; DMSO: dimethyl sulfoxide; DMEM: Dulbecco's modified eagle medium; MTT: dimethylthiazol diphenyltetrazolium bromide; SRB: sulforhodamine; FBS: fetal bovine serum; 293T cell: embryonic kidney cell; HeLa cell: cervical cancer cell; MCF-7: breast cancer cells; HIV-1: human immunodeficiency virus-1; IPTG: isopropyl-beta-D-thiogalacto-pyranoside; GAPDH: glyceraldehyde-3-phosphate dehydrogenase; IL-2, -4, -6, -10: interleukin-2, -4, -6, -10; TNF-a: tumor necrosis factor-a.

\section{Acknowledgements}

None.

\section{Authors' contributions}

$J R, Y Y$ and FL designed the experiments. JR, YY and $Y S$ executed the experiments, analyzed all data and produced figures. JR, FL and TNB provided technical and theoretical support. FL conceived and coordinated the study, and helped in the drafting of the manuscript. JR and FL wrote and revised the manuscript. TBN gave advice in the study and edited the manuscript. All authors read and approved the final manuscript.

\section{Funding}

This study has been funded by National Natural Science Foundation (Grant No. 31870006) and the award of Health and Medical Research Fund (No. 12131221) from Food and Health Bureau, The Government of Hong Kong Special Administrative Region.

Availability of date and materials

All datasets on which the conclusions of the manuscript rely are presented in the main paper 


\section{Ethics approval and consent to participate}

The investigations described herein did not involve human participants, human data or human tissues. All applicable international guidelines for the care and use of animals were followed.

\section{Consent for publication}

Not applicable.

\section{Competing interests}

The authors declare that they have no competing interests.

Received: 15 November 2019 Accepted: 18 November 2019

Published online: 03 December 2019

\section{References}

Coghill AE, Schenk JM, Mahkoul Z, Orem J, Phipps W, Casper C (2017) Omega-3 decreases interleukin-6 levels in HIV and HHV-8 co-infected patients: results from a randomized supplementation trial in Uganda. AIDS 32(4):505-512. https://doi.org/10.1097/QAD.0000000000001722

Das A, Rahman MI, Ferdous AS, Amin A, Rahman MM, Nahar N, Uddin MA, Islam MR, Khan H (2017) An endophytic Basidiomycete, Grammothele lineata, isolated from Corchorus olitorius, produces paclitaxel that shows cytotoxicity. PLoS ONE 12(6):e0178612. https://doi.org/10.1371/journ al.pone.0178612

Flores-Bustamante ZR, Rivera-Orduna FN, Martinez-Cardenas A, Flores-Cotera LB (2010) Microbial paclitaxel: advances and perspectives. J Antibiot 63(8):460-467. https://doi.org/10.1038/ja.2010.83

Frense D (2007) Taxanes: perspectives for biotechnological production. Appl Microbiol Biot 73(6):1233-1240. https://doi.org/10.1007/s0025 3-006-0711-0

Hao X, Pan J, Zhu X (2013) Taxol producing fungi. In: Ramawat KG, Mérillon J-M (eds) Natural products: phytochemistry, botany and metabolism of alkaloids, phenolics and terpenes. Springer, Berlin, pp 2797-2812

Herdeg C, Oberhoff M, Baumbach A, Blattner A, Axel DI, Schroder S, Heinle H, Karsch KR (2000) Local paclitaxel delivery for the prevention of restenosis: biological effects and efficacy in vivo. J Am Coll Cardiol 35(7):1969-1976. https://doi.org/10.1016/S0735-1097(00)00614-8

Ishkuh FA, Javanbakht M, Esfandyari-Manesh M, Dinarvand R, Atyabi F (2014) Synthesis and characterization of paclitaxel-imprinted nanoparticles for recognition and controlled release of an anticancer drug. J Mater Sci 49(18):6343-6352. https://doi.org/10.1007/s10853-014-8360-7

Ismaiel AA, Ahmed AS, Hassan IA, El-Sayed ER, Karam El-Din AA (2017) Production of paclitaxel with anticancer activity by two local fungal endophytes, Aspergillus fumigatus and Alternaria tenuissima. Appl Microbiol Biot 101(14):5831-5846. https://doi.org/10.1007/s00253-017-8354-x

Jennewein S, Croteau R (2001) Taxol: biosynthesis, molecular genetics, and biotechnological applications. Appl Microbiol Biot 57:13-19. https://doi. org/10.1007/s002530100757

Kasaei A, Mobini-Dehkordi M, Mahjoubi F, Saffar B (2017) Isolation of taxolproducing endophytic fungi from iranian yew through novel molecula approach and their effects on human breast cancer cell line. Curr Microbiol 74(6):702-709. https://doi.org/10.1007/s00284-017-1231-0

Krawczyk E, Luczak M, Majewska A (2005) Antiviral and cytotoxic activities of new derivatives of natural sesquiterpenes and taxol. Med Dosw Mikrobiol 57(1):93-99

Kusari S, Hertweck C, Spitellert M (2012) Chemical ecology of endophytic fungi: origins of secondary metabolites. Chem Biol 19(7):792-798. https:// doi.org/10.1016/j.chembiol.2012.06.004

Lasala JM, Stone GW, Dawkins KD, Serruys PW, Colombo A, Grube E, Koglin J, Ellis S (2006) An overview of the TAXUS express, paclitaxel-eluting stent clinical trial program. J Interv Cardiol 19(5):422-431. https://doi.org/10.11 11/j.1540-8183.2006.00183.x

Li N, Ng TB, Wong JH, Qiao JX, Zhang YN, Zhou R, Chen RR, Liu F (2013) Separation and purification of the antioxidant compounds, caffeic acid phenethyl ester and caffeic acid from mushrooms by molecularly imprinted polymer. Food Chem 139(1-4):1161-1167. https://doi.org/10.1016/j. foodchem.2013.01.084

Li N, Zhao LJ, Ng TB, Wong JH, Yan Y, Shi Z, Liu F (2015) Separation and purification of the antioxidant compound hispidin from mushrooms by molecularly imprinted polymer. Appl Microbiol Biot 99(18):7569-7577. https://doi.org/10.1007/s00253-015-6499-z

Li P, Wang T, Lei F, Peng X, Wang H, Qin L, Jiang J (2017) Preparation and evaluation of paclitaxel-imprinted polymers with a rosin-based crosslinker as the stationary phase in high-performance liquid chromatography. J Chromatogr A 1502:30-37. https://doi.org/10.1016/j.chroma.2017.04.048

Oberlies NH, Kroll DJ (2004) Camptothecin and taxol: historic achievements in natural products research. J Nat Prod 67(2):129-135. https://doi. org/10.1021/np030498t

Otiti-Sengeri J, Colebunders R, Reynolds SJ, Muwonge M, Nakigozi G, Kiggundu V, Nalugoda F, Nakanjako D (2018) Elevated inflammatory cytokines in aqueous cytokine profile in HIV-1 infected patients with cataracts in Uganda. BMC Ophthalmol 18:12. https://doi.org/10.1186/ s12886-018-0680-y

Shankar Naik B (2019) Developments in taxol production through endophytic fungal biotechnology: a review. Orient Pharm Exp Med 19(1):1-13. https //doi.org/10.1007/s13596-018-0352-8

Skehan P, Storeng R, Scudiero D, Monks A, McMahon J, Vistica D, Warren JT, Bokesch H, Kenney S, Boyd MR (1990) New colorimetric cytotoxicity assay for anticancer-drug screening. J Natl Cancer Inst 82(13):1107-1112

Somjaipeng S, Medina A, Kwasna H, Ordaz Ortiz J, Magan N (2015) Isolation, identification, and ecology of growth and taxol production by an endophytic strain of Paraconiothyrium variabile from English yew trees (Taxus baccata). Fungal Biol 119(11):1022-1031. https://doi.org/10.1016/j.funbi 0.2015.07.007

Stebbing J, Wildfire A, Portsmouth S, Powles T, Thirlwell C, Hewitt P, Nelson M Patterson S, Mandalia S, Gotch F (2003) Paclitaxel for anthracycline-resistant AIDS-related Kaposi's sarcoma: clinical and angiogenic correlations. Ann Oncol 14:1660-1666. https://doi.org/10.1093/annonc/mdg461

Visalakchi S, Muthumary J (2010) Taxol (anticancer drug) producing endophytic fungi: an overview. Int J Pharma Bio Sci 1(3):1-9

Wang X, Wang C, Sun YT, Sun CZ, Zhang Y, Wang XH, Zhao K (2015) Taxol produced from endophytic fungi induces apoptosis in human breast, cervical and ovarian cancer cells. Asian Pac J Cancer Prev 16(1):125-131. https://doi.org/10.7314/apjcp.2015.16.1.125

Yuan L, Wu LH, Chen JA, Wu QA, Hu SH (2010) Paclitaxel acts as an adjuvant to promote both Th1 and Th2 immune responses induced by ovalbumin in mice. Vaccine 28(27):4402-4410. https://doi.org/10.1016/j.vacci ne.2010.04.046

Zhang B, Maiti A, Shively S, Lakhani F, McDonald-Jones G, Bruce J, Lee EB, Xie SX, Joyce S, Li C, Toleikis PM, Lee VMY, Trojanowski JQ (2005) Microtubulebinding drugs offset tau sequestration by stabilizing microtubules and reversing fast axonal transport deficits in a tauopathy model. Proc Natl Acad Sci USA 102(1):227-231. https://doi.org/10.1073/pnas.0406361102

Zhou X, Zhu H, Liu L, Lin J, Tang K (2010) A review: recent advances and future prospects of taxol-producing endophytic fungi. Appl Microbiol Biot 86(6):1707-1717. https://doi.org/10.1007/s00253-010-2546-y

\section{Publisher's Note}

Springer Nature remains neutral with regard to jurisdictional claims in published maps and institutional affiliations. 